\title{
CHEMICAL AND MINERALOGICAL ANALYSES OF COAL-BEARING STRATA IN THE APPALACHIAN BASIN
}

\author{
Frank T. Dulong ${ }^{1}$, Nick Fedorko ${ }^{2}$, John J. Renton $^{3}$, and C. Blaine Cecil ${ }^{1}$
}

${ }^{1}$ U.S. Geological Survey, Reston VA, ${ }^{2}$ West Virginia Geological and Economic Survey, Morgantown, WV, ${ }^{3}$ West Virginia University, Morgantown WV

\section{Introduction}

Past, present, and future coal mining in the Appalachian basin has caused, now causes, and will continue to cause changes in hydrologic conditions that result in oxidation and dissolution of minerals in coal and coal-bearing strata. Once mines are closed and abandoned, the oxidation and dissolution of minerals in coal-bearing strata often results in contaminated mine drainage (CMD). CMD may develop when closed water-filled underground mines overflow to the surface through leakages in mine seals, through fractures induced by mining, or through natural fractures. In contrast to underground mines, CMD develops after closure of surfaces mines when the ground and surface water that infiltrates and percolates through materials disturbed by mining and reclamation subsequently discharges to the surface and into surface streams.

The degree of development of CMD is highly dependent on the geologic history of coal-bearing strata that have undergone disturbance by mining. The geologic history controls the chemical and mineralogical composition of coal and coal-bearing strata (Cecil and others, 1985) and the geologic history is a primary control on pre-mining and post-mining hydrology. Although mining-related environmental degradation of streams occurs throughout the coal fields in the Appalachian basin, CMD is most acute in Pennsylvania, Maryland, Ohio, and northern West Virginia (the northern coal field of this report) where mining primarily occurs in upper Middle and Upper Pennsylvanian strata. It is in upper Middle and Upper Pennsylvanian strata where the oxidation of pyrite results in the generation of sulfuric acid, which leads to acidic mine drainage and the associated leaching of certain metals, particularly iron, aluminum, and manganese (see Brady and others, 1998). In contrast, CMD is relatively rare in the coal fields of southern West Virginia, western Virginia, and eastern Kentucky (the southern coal field of this report) in lower Middle and Lower Pennsylvanian strata. Mining disturbances in lower Middle and Lower Pennsylvanian strata occasionally result in manganese contamination, and even more rarely, minor acidic drainage may occur. In contrast to the notorious CMD problems in the northern fields, water contained in abandoned underground mines in the southern field is often potable, and is sometimes used as municipal water supplies. Thus, the regional and stratigraphic variations in the chemical and mineralogical properties of coal and coal-bearing strata are highly variable. Therefore, long-term goals for this study have been developed as follows:

1) evaluate the geologic controls on the chemistry, mineralogy, and spatial distribution (both regional and stratigraphic) of deleterious substances in coal and coal-bearing strata in the Appalachian basin; 
2) develop methodologies that can be used to predict stratigraphic trends in materials that control CMD; and

3) develop methodologies for specific stratigraphic intervals that can be used to predict the regional spatial variability of materials that control CMD

This preliminary report includes both stratigraphic and regional data on the chemistry and mineralogy of coal-bearing strata in both the northern and southern coal fields of the Appalachian basin.

\section{Methods}

This report contains data obtained from a pilot study that was undertaken to develop a stratigraphic and regional framework to preliminarily quantify the spatial variability of materials that contribute to CMD. This report presents chemical and mineralogical data from seven cores extracted from both the northern and southern coal fields (Figure 1) as part of the pilot study. Data from the eighth site (designated USGS-5 in the drilling program), which was cored in the Eastern Interior basin for the Indiana Geological Survey, are not included in this report. Coring locations in the Appalachian basin were selected to provide preliminary data on the stratigraphic and regional distribution of rock mineralogy and rock chemical properties. The stratigraphic intervals that were cored at each locality are shown in Figure 2.

\section{Coring}

Coring operations were conducted by wireline methods under the direction of either the West Virginia Geological and Economic Survey (WVGES) or the U.S. Geological Survey (USGS). Coring sites were selected based on the following:

1) stratigraphic interval likely to be encountered and the degree of CMD-producing materials likely to be contained therein, and

2) acquisition of samples that would provide basin-scale (regional) information.

Cores were described in the field upon recovery, followed by boxing and transport to the WVGES.

\section{Chemical and mineralogical analyses of core samples}

Cores were divided into one-foot increments and each increment was split in half lengthwise by cutting with a rock saw. The one-foot-increment samples were submitted to the analytical laboratories at the Department of Geology, West Virginia University (WVU) where each sample was ground to minus 60 mesh. Standard chemical methods and X-ray diffraction methods were used to analyze each of the ground samples. Major and minor element concentrations (X-ray fluorescence) and acid-base accounting parameters (wet chemical) were determined for each sample. X-ray diffraction analyses produced semi-quantitative determinations of the mineral composition of each sample.

Standard acid-base accounting methods were modified to remove siderite from samples prior to the determination of neutralization potential. This precaution was taken because, in the standard neutralization potential testing, siderite titrates as calcium carbonate, which inflates the 
neutralization potential results (Wiram, 1992). In nature, oxidation of iron in siderite produces hydrogen ions that contribute to acidity rather than to neutralize acidity (summarized in Brady and others, 1998, and papers therein). The method used in this study reduces or eliminates false neutralization potential analyses caused by the presence of siderite.

\section{Down-hole chemical wireline logging}

In addition to chemical and mineralogical testing of core samples as noted above, down-hole geochemical wireline logging (GCL) was also tested as an alternative method of chemical characterization of coal-bearing strata. To summarize, GCL bombards the sidewall of a borehole with neutrons from a source contained in the logging tool. Chemical elements in the sidewall strata then emit X-rays that have a characteristic wave length. Sensors within the tool measure both the wave length and intensity of the X-rays, which provide a measure of the elements present and their concentrations. The technique has the advantage of providing "real time" analyses at a drill site including a down-hole log of net neutralization potential. The technique also has the potential advantage of analyzing a rock volume that is larger than the core samples because the depth of neutron penetration into the side wall is up to 1.5 meters. However, the GCL method was rejected as a quantitatiive method after comparing the down-hole logging results with the standard core analyses. It was determined that GCL provides a good qualitative stratigraphic record of elements of interest such as iron, sulfur, and calcium in coal bearing strata. GCL logs permit identification of stratigraphic intervals enriched in these and other elements. Although GCL was precise (runs were reproducible), the accuracy remained ambiguous, even after tests were conducted on seven different holes. Further testing will be required by the companies that provided the logging service in order to determine and refine the accuracy of the GCL methodology. Testing of GCL was terminated in this study because tool accuracy could not be demonstrated.

\section{Results}

Results are available for the one-foot increment samples from seven cores (Figs. 1 and 2) of coal-bearing strata in the Appalachian basin. The data are available at http://pubs.usgs.gov/of/2002/of02-489 and provide the following for each core: 1) location of coring site, 2) details of cored stratigraphic interval, 3) geologist's lithologic descriptions of the cores, 4) percent sulfur values of one-foot increment samples, 5) major and selected minor element analyses of one-foot increment samples, 6) semi-quantitative mineralogical analyses of one-foot increment samples, and 7) acid-base accounting analyses of one-foot increment samples. The present report is limited to presentation of data. 


\section{References}

Brady, K.B.C., Smith, M.W., and Schueck, J. (eds), 1998, Coal mine drainage prediction and pollution in Pennsylvania: The Pennsylvania Department of Environmental Protection, Harrisburg, PA, 18 Chapters.

Cecil, C.B., Stanton, R.W., Neuzil, S.G., Dulong, F.T., Ruppert, L.F., and Pierce, B.J., 1985, Paleoclimate controls on Late Paleozoic sedimentation and peat formation in the central Appalachian basin: International Journal of Coal Geology, v. 5, p. 195-230.

Wiram, V.P., 1992, Siderite masking: a factor to consider in overburden acid-base balancing, in Proceeding, of the WV Surface Mine Drainage Task Force Symposium, West Virginia University, Morgantown, WV. 


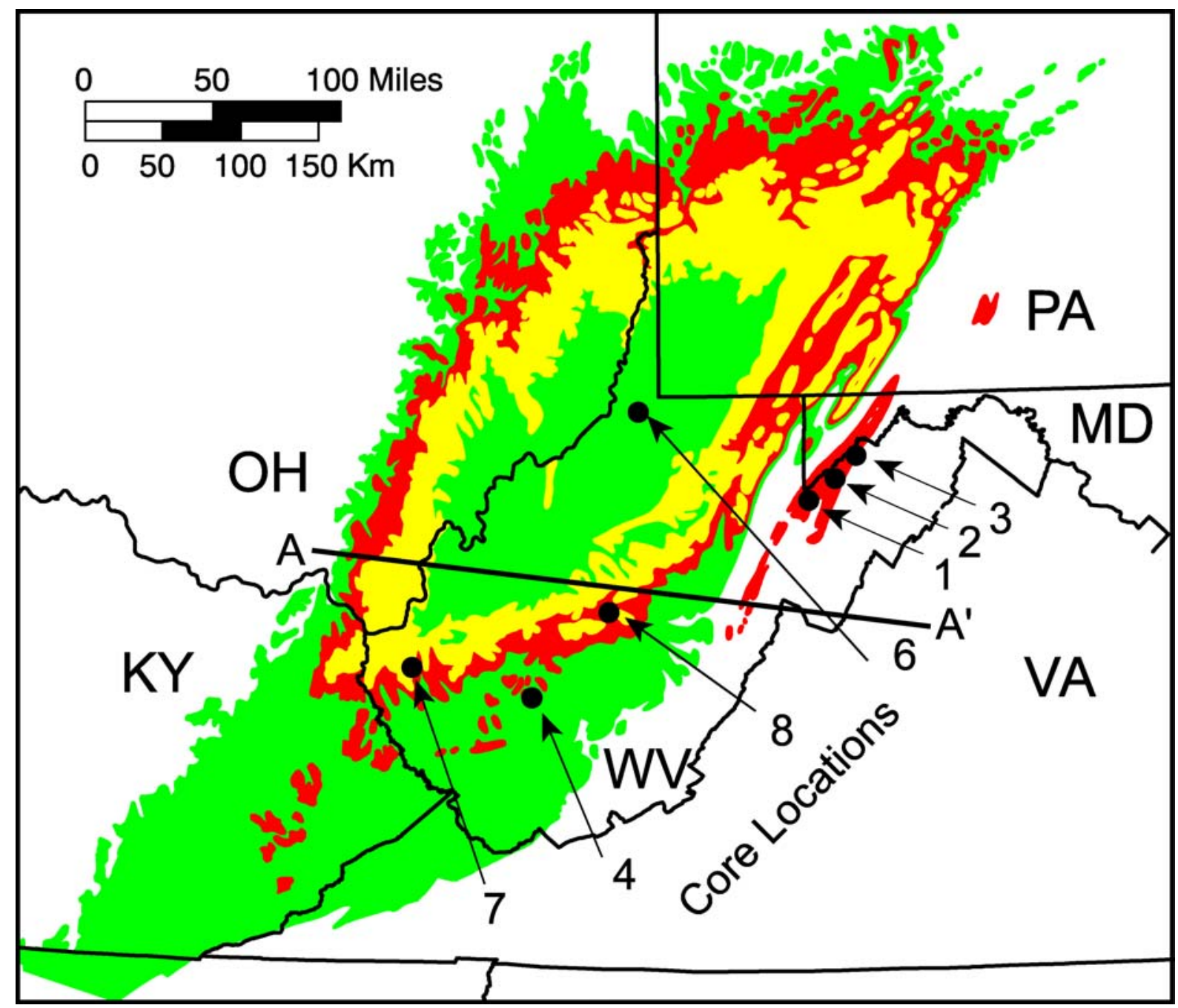

Figure 1. Distribution of Pennsylvanian coal-bearing strata in the Appalachian region study area. Line A-A' approximately separates the northern and southern coal fields. Colors depict the potential for contaminated mine drainage (CMD) from surface mines as follows: 1) green areas have a low potential, 2) red areas have a high potential, and 3) yellow areas have an intermediate potential. Numbered dots indicate core-hole locations. 


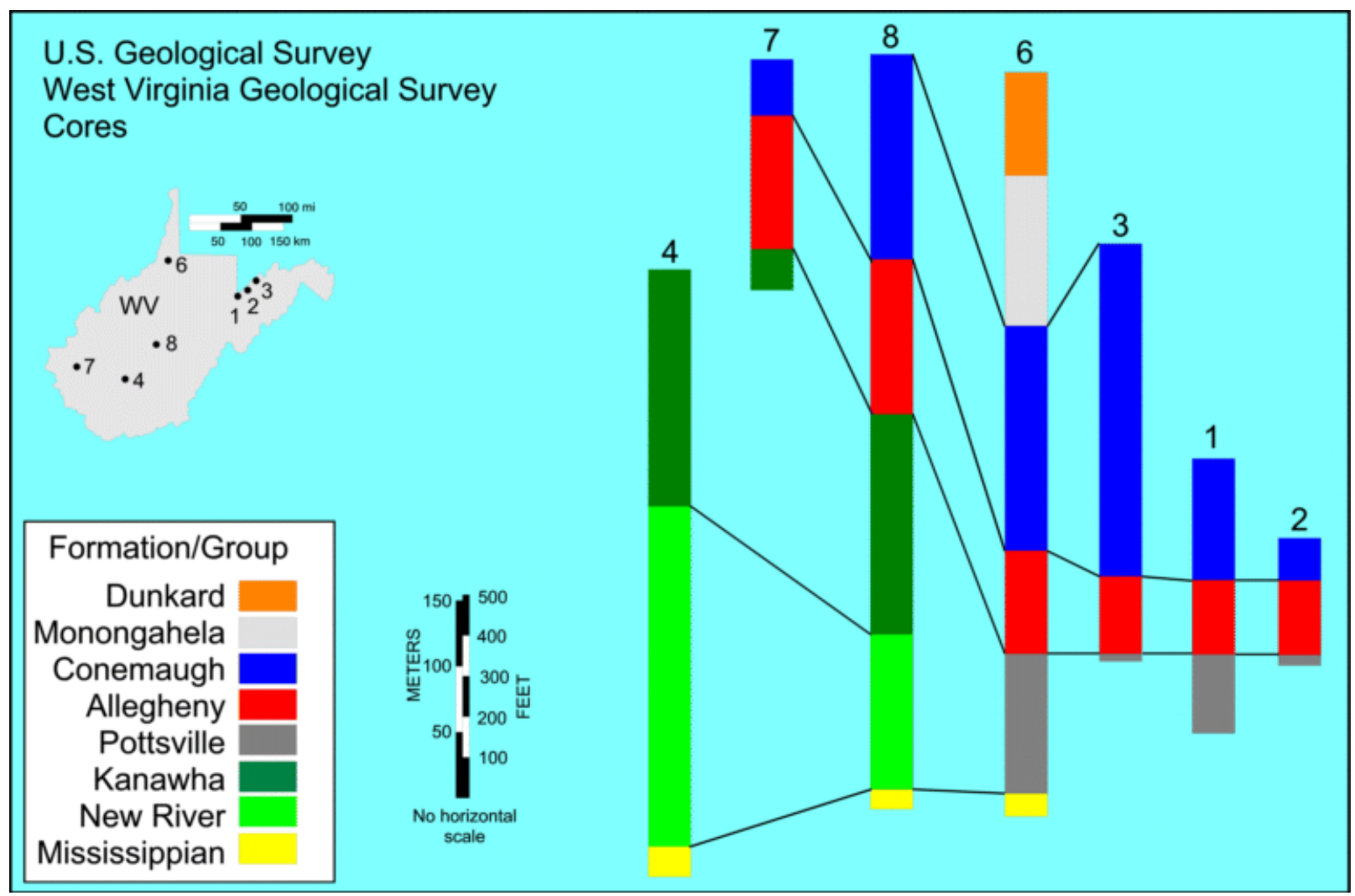

Figure 2. Regional correlations of Mississippian and Pennsylvanian stratigraphic intervals that were cored at each locality. Lines connect stratigraphic units among cores. 